\title{
ENTRE CAPTURAS BIOPOLÍTICAS E ESTRATÉGIAS DE RESISTÊNCIA LGBT: UM ENSAIO SOBRE A LÓGICA FÁRMACO-MORALIZANTE NA PROFILAXIA PRÉ-EXPOSIÇÃO - PrEPi
}

\author{
Jamil Cabral Sierraii \\ Dagmar Estermann Meyerii
}

\begin{abstract}
Resumo: Apoiando-se nos estudos foucaultianos, este artigo discute processos de inclusão social da população LGBT, na interface educação e saúde, especialmente no que diz respeito às estratégias biopolíticas de controle das sexualidades LGBT. Para isso, tomamos como objeto de análise enunciados em torno da Profilaxia Pré-exposição - PrEP. Nossa aposta é a de que programas como a PrEP podem ser pensados em um duplo analítico. De um lado, tais programas ajustam-se ao contexto da governamentalidade biopolítica neoliberal, a partir de um deslocamento, na atualidade, na forma de prevenção de doenças: de uma lógica comportamental-moralizante, para uma outra lógica que chamamos de fármaco-moralizante. De outro lado, tais programas podem, concomitantemente, a partir dos modos pelos quais as pessoas subvertem o uso dessas últimas formas de prevenção, funcionar como estratégia de resistência criada no interior dos próprios dispositivos de controle.
\end{abstract}

Palavras-chave: Biopolítica; Sexualidade; LGBT; PrEP; Foucault.

\section{BETWEEN BIOPOLITICAL CAPTURES AND STRATEGIES OF LGBT RESISTANCE: ESSAY ABOUT PHARMACO-MORALIZING LOGIC IN PRE-EXPOSURE PROPHYLAXIS - PrEP}

\begin{abstract}
Inspired by Foucauldian studies, this paper discusses the process of social inclusion of LGBT population at the interface between education and health, focusing on the biopolitical strategies by which LGBT sexualities are controlled. For that, we analyze discourses around pre-exposure prophylaxis - PrEP. Our effort is to think of programs as $\operatorname{PrEP}$ in a two ways movements of analysis. On the one hand, such programs adjust to the neoliberal biopolitical governmentality context in current ways of prevention of sexually transmitted diseases: of a behavioral-moralizing logic to another that we call pharmacomoralizing. On the other hand, concomitantly, such programs can also work as resistance strategies inside the dispositive of control depending on the ways in which people subvert the uses of these forms of prevention.
\end{abstract}

Key-Words: Biopolitics. Sexuality. LGBT. PrEP. Foucault. 


\section{Introdução}

É bem sabido que a educação e a saúde (escolas, hospitais, clínicas, centros psicopedagógicos, centros de pesquisas médico-farmacológicas, dentre outros aparatos) têm se constituído como grande lugar em que se processam as produções de verdade sobre o sexo, os gêneros e as sexualidades. É bem sabido, também, que a educação e a saúde têm se dedicado, através de seus porta-vozes e especialistas (professores, pedagogos, psicopedagogos, psicólogos, médicos etc.) a falarem a verdade sobre o sexo e a produzirem e/ou definirem, por meio de seus saberes, quem são os corpos inviáveis e quem são os corpos viáveis para as políticas públicas de educação e saúde, por exemplo. Em outros termos, [...] o objetivo das novas formas de governamento ${ }^{\text {iv }}$ dos corpos e das almas [...] é a aquisição de competências adequadas ao mercado neoliberal, tendo em vista a produção de corpos viáveis. (CÉSAR, 2010, p. 232).

A educação e a saúde se tornam, assim, campos privilegiados de produção das identidades, constituindo-se, sobremaneira, como lugares, por meio do quais, se reivindica a inclusão, sobretudo por parte dos movimentos sociais ${ }^{\mathrm{v}}$. As lutas identitárias, especialmente nos últimos 15 anos, ao promoverem a inclusão como um imperativo a ser buscado, acabaram deixando tantos outros à exclusão, reforçando a heteronormatividade e potencializando os efeitos gerados pelo dispositivo da sexualidade (FOUCAULT, 2001a) e pelos discursos normalizadores. Nessa direção, ao tomarmos

[...] a inclusão como um imperativo implica, como decorrência, o questionamento de três entendimentos correntes em nossa cultura. Em primeiro lugar, a inclusão social tem sido entendida como algo natural. Em segundo lugar, ela tem sido compreendida como algo bom em si mesmo. Por fim, ela tem sido apresentada como necessária. Assim assumida, a inclusão social estaria desde sempre aí, esperando para ser efetivada. É a isso que chamamos de imperativo. (MEYER; DAL'IGNA; KLEIN; SILVEIRA, 2014, p.1010).

Nesse panorama, os próprios sujeitos da diversidade sexual e de gênero passam, respaldados pelos movimentos sociais, a reivindicar acesso à educação e à saúde, usando, como estratégia, cada vez mais um dizer sobre si mesmo, uma espécie de outing da nossa época, em que não basta apenas revelar-se homossexual; antes, é preciso confessar a verdade sobre seu sexo e oferecer aos aparatos de governamento (FOUCAULT, 2008b), insumo para o estabelecimento de uma certa conformação identitária do corpo e da sexualidade. Com isso, esses sujeitos ajustam-se aos projetos educacionais e de saúde normalizadores que definem qual é a viabilidade-moral-econômica dos corpos e das práticas sexuais LGBT, bem como de que forma esses corpos devem ocupar seus lugares a partir das categorias identitárias a eles conferidas (SIERRA, 2013b).

Esse processo de conformação identitária do corpo, do sexo e da sexualidade vem sendo tramado já há algum tempo. Ele se desdobra dos movimentos liberacionistas dos anos 1970, que operavam no sentido 
de construir identidades bem estabelecidas e, de certa forma, inseridas no âmbito do "bom comportamento", do "comportamento saudável", a fim de, por meio dessa estratégia, tentar assegurar à população LGBT um lugar na ordem, tanto social, quanto econômica (bens de consumo, oportunidades de emprego etc.).

Em meados dos anos 1970, o objetivo do movimento era transformar o sistema social entendido como causa da opressão. Assim, como as feministas criticavam instituições como o casamento e família por apoiarem a opressão das mulheres, e pressionavam por uma mudança social radical, até mesmo revolucionária, algo semelhante era feito pelo movimento de liberação gay. (SPARGO, 2006, p.26)

Além disso, esses movimentos liberacionistas criaram disputas internas em vários segmentos dos movimentos homossexuais dessa época, em função da tônica higienista e moralizante que, nesse momento, era tomada como fundamento na estratégia de luta dos movimentos homossexuais. Tal estratégia gerou muitas críticas, por exemplo, por parte de grupos que tentavam se colocar fora desse campo de atuação política e que buscavam outras formas de fazer representar seus corpos, suas práticas e seus prazeres, dissociando-os dessa estratégia de cunho mais moral-econômico. Grupos de lésbicas masculinas, sadomasoquistas, gays afeminados, bem como de travestis e transexuais (que começam a se organizar de forma mais coesa), começam a emergir - juntamente com o aparecimento da Aids no início dos anos 1980 - e a questionar essas retóricas higienistas/moralizantes, ao mesmo tempo em que provocam fissuras no movimento homossexual, em duas direções. A primeira direção, mais evidente, foi a consequente fragmentação identitária, em que cada identidade estabelecia suas pautas e definia sua ação no âmbito da reivindicação por direitos - o que resultaria, mais tarde, na famosa "sopa de letrinhas" LGBT (FACHINNI, 2005). A segunda direção, menos explícita, tem a ver com o fato de que, em função dessas divergências internas do movimento homossexual, começamos a presenciar outras formas de ação política e epistemológica, mais descoladas do essencialismo estratégico identitário. ${ }^{\mathrm{vi}}$

De qualquer forma, é nesse contexto oitentista que a epidemia da Aids começa ser a razão para a constituição de um conjunto de estratégias biopolíticas de controle dos corpos e das práticas sexuais de LGBT. (SIERRA, 2013a). Tais estratégias biopolíticas vão reforçar ainda mais o saber-poder sobre o corpo, o sexo e, por extensão, sobre a vida desses sujeitos. Dessa forma, a doença provoca não só a necessidade de saber as causas da doença, mas também a urgência de se investigar - para controlar - os supostos comportamentos imorais e desviantes que levariam à contaminação pelo vírus.

Neste processo, os homossexuais começam a ser alvo das flechadas dos saberes médico-científicos, que (até recentemente) entendiam a Aids como uma doença ligada à homossexualidade, uma espécie de "peste gay". Assim, a Aids se estabelecia, na década de 1980, como falha moral dos sujeitos homossexuais e cada vez mais a culpabilidade sobre a doença recai sobre os ombros de gays, lésbicas, bissexuais, travestis e transexuais já que, por estar associada ao comportamento 
sexual, via-se a doença como resultado de irresponsabilidade, prevaricação, despudoramento, obscenidades no exercício da sexualidade [...]. (SIERRA, 2013a, p.120).

Ou, ainda, como diz Trevisan:

Em resumo, salvo prova em contrário, o doente de Aids é culpado de sua doença. Se diante da fatalidade do câncer as pessoas sadias sentem pena, diante da Aids elas tendem a sentir raiva, a partir de um julgamento moral que a vê como doença do corpo resultante de uma alma conspurcada. (TREVISAN, 2002, p.437).

Desse momento em diante, os fatos que se seguem são já bem conhecidos. A homossexualidade passa a estar ligada diretamente à Aids, em grande medida sendo confundida com a própria doença, espécie de lugar onde o "mal" se alojaria em função de comportamentos inseguros e de práticas promíscuas e imorais. A população LGBT em geral, e os homens gays e as travestis em particular, passam a ser cada vez mais interpretados como responsáveis pela propagação do vírus, despertando uma espécie de pânico moral $^{\text {vii }}$ na sociedade.

É nesse contexto que surge, por exemplo, o Grupo Gay da Bahia, um dos primeiros grupos a criar uma pauta de luta e enfrentamento contra o vírus no Brasil. O grande objetivo, era, portanto, lutar pela diminuição do preconceito e contra a discriminação de homossexuais, especialmente em um tempo em que a epidemia da Aids estava completamente associada ao público gay, a ponto da doença ser difundida como um mal ligado ao "instinto gay”, ou como diz Trevisan (2002), ao “desejo gay”. Os esforços consistiam em desassociar a homossexualidade da Aids, bem como criar condições para sua retirada da Classificação Internacional das Doenças - CID. ${ }^{\text {viii }}$ Como nessa época não havia no Brasil nenhum programa de combate à Aids, foi o movimento homossexual o primeiro a organizar campanhas de combate à epidemia, lançando, ao poder público, demandas de enfrentamento do vírus e tratamento da doença. Temos, aqui, aliás, o embrião do que, mais tarde, se tornaria um dos pilares da grande parceria entre Estado e movimentos sociais $L G B T$ e que consolidará a estratégia de instituir as políticas de identidade como a grande plataforma, tanto para o Estado como para a militância, de combate à homofobia e de luta em favor dos direitos homossexuais no contexto brasileiro. (SIERRA, 2013b, 2019).

Com isso, uma série de medidas higienistas passam a ser postas em prática, como fechamento de saunas gays, tratamentos psicológicos de "cura" da homossexualidade e, especialmente, um investimento maciço em prevenção da doença, em que a camisinha se converte na grande estratégia de controle. Se não era possível interromper aquilo que era interpretado como comportamento imoral, ao menos que tais práticas sexuais, então, fossem feitas de forma "protegida". Surgem, assim, as retóricas de "sexo seguro" e um grande investimento em campanhas de prevenção e combate da doença ${ }^{i x}$ que, em grande medida, ansiavam ainda 
[...] a mesmidade, uma vez que vazam delas feixes discursivos que sustentam o pavor à diferença e que negam a multiplicidade sexual se ela estiver escapulindo à norma do padrão de consumo e da consciência burguesa. A normalização aparece agora, da forma como vejo, no jogo que seduz a alteridade a se expor, para que, ao saber dela, seja possível maquinar caminhos de mantê-la docilmente confortada à moral burguesa e à ordem do consumo. A normalização do presente se ajusta às reconfigurações biopolíticas de gerenciamento da vida. (SIERRA, 2014, p.146).

A partir de 1990, quando a homossexualidade é retirada da Classificação Internacional de Doenças - CID, pela OMS (Organização Mundial da Saúde), temos apenas uma relativa mudança. Relativa porque ao mesmo tempo em que a retirada da CID tensionou os discursos até então construídos em torno da doença e das suas formas de contágio ligadas exclusivamente a homossexuais (até porque aumenta nessa época o número de casos de pessoas heterossexuais infectadas), ela não foi capaz de subverter totalmente os discursos que associavam (e ainda associam) a doença à ideia de "comportamento sexual". Aliás, foi justamente essa transição - da Aids ligada ao homossexual como espécie (FOUCAULT, 2001a), para a Aids ligada ao "comportamento sexual” de um grupo específico - que será responsável pela sofisticação das estratégicas biopolíticas de controle da doença e, por consequência, dos corpos e das práticas sexuais LGBT - mesmo que, paradoxalmente, essa transição tenha possibilitado, também, que diferentes grupos, ao promoverem sua luta contra a Aids, pudessem expressar seus corpos e suas práticas por outros caminhos, mais dissociados da lógica identitária. De um lado "comportamento sexual" que precisa ser controlado; de outro lado, práticas que surgem como outras experiências de relação com o corpo, o sexo, os gêneros e as sexualidades. Nos parece - queremos apostar nisso - que a Aids foi capaz de acionar essa dupla dimensão, dado seu impacto gigantesco e que, até hoje, reverbera. Ao mesmo tempo em que criou condições de possibilidade para a constituição de corpos e práticas não identitários, abrindo inclusive caminho para a própria teorização queer $^{x}$ se constituir, despertou cada vez mais saberes médico-biológicos que tentam decifrar o sexo verdadeiro, dando a "[...] cada um sua identidade sexual primeira, profunda, determinada e determinante [...]" (FOUCAULT, 1982, p.2).

Assim, a epidemia da Aids acabou por reconfigurar as coalizões de enfrentamento da doença e de luta política. O combate ao vírus reconfigurou a ideia de identidade como única alternativa, já que para determinados grupos - antes de se vincularem em função de uma identidade em comum - valeria mais formar grupo em torno de como viviam seus corpos, constituíam suas práticas e experimentavam seus prazeres. Nos Estados Unidos, em particular, determinados grupos organizaram-se no sentido de criar outras formas de resistência, como fez o ACT UP. "A estratégia do ACT UP concentrou-se em resistir aos efeitos de poder e saber que se manifestavam em instituições médicas e de assistência pública, em companhias de seguro e em vários outros contextos." (SPARGO, 2006, p.33). Enquanto isso, em solo brasileiro, em um caminho um pouco distinto do que aconteceu nos Estados Unidos, em grande parte 
pavimentado pela parceria entre Estado e movimentos sociais LGBT, presenciamos um processo que Larissa Pelúcio (2009) chama de "SIDAdanização", ou seja, a Aids funcionando como elemento a partir do qual seriam empreendidas as biopolíticas de inclusão e de promoção da cidadania dos sujeitos LGBT. ${ }^{\mathrm{xi}}$

De um jeito ou de outro, seja reconfigurando a forma de organização de determinados movimentos contra as estratégias de captura das subjetividades LGBT, seja intensificando as estratégias de controle sobre corpos e práticas sexuais, a Aids colocou

[...] as escolas, as famílias, a mídia, os políticos e, pasmem!, até as igrejas mais reticentes $[. .$.$] a se engajar com maior ou menor energia, numa generalizada (porque$ compulsória, sem escolha) campanha em busca dos meandros da sexualidade, essa esfinge que insolentemente exigia: "decifra-me, ou te devorarei". A sociedade passou a debater amplamente argumentos a favor e contra sexo anal, sexo oral, perversões, quantidade de parceiros/as, uso de camisinha, sexo seguro, doenças venéreas, métodos anticoncepcionais, casamento entre pessoas do mesmo sexo, convivência ou não da adoção de crianças em famílias não-padronizadas etc. (TREVISAN, 2002, p. 463)

Dessa forma, entra em jogo, com a epidemia, não só o controle de identidades específicas exclusivamente, mas também o controle de corpos, práticas e prazeres que punham sob ameaça um projeto heteronormativo maior: colocar em perigo a própria heterossexualidade e seus contratos de gênero, sexuais, matrimoniais e reprodutivos.

Em face desse histórico, arriscamos argumentar que a viabilidade-moral-econômica dos corpos e práticas sexuais LGBT tem passado por uma reconfiguração desde então. Nos dias de hoje, ela tende a ser exercida muito mais por meio de estratégias fármaco-morais, a partir das quais se constroem e sustentam os discursos de prevenção. Se anteriormente a viabilidade-moral-econômica das sexualidades LGBT era buscada por meio de discursos de prevenção em que a protagonista era camisinha (um processo que chamamos de comportamental-moralizante), hoje ela tem cedido lugar para o Truvada ${ }^{x i i}$ (um processo que chamamos de fármaco-moralizante). Queremos arriscar dizer que, na contemporaneidade, grande parte dos discursos que acolhem a população LGBT surge do solo que alimenta a noção de que só por meio de uma lógica fármaco-moralizante da sexualidade é possível abandonar o lugar de abjeção até então relegado a essas pessoas. Nossa suspeita tem se dado, portanto, no sentido de pensar que a viabilidade-moraleconômica da população LGBT, bem como sua inclusão no campo da educação e da saúde, tem acontecido, par-e-passo, a esse processo fármaco-moralizante que, nos dias de hoje, age como forma de governamento biopolítico desses sujeitos. No entanto, de forma concomitante, há um tensionamento, arriscamos também ensaiar, que é produzido na própria lógica fármaco-moralizante, a partir de como determinadas pessoas exercitam a resistência à norma ao fazerem uso, estrategicamente, de formas de prevenção como a do $\operatorname{PrEP}$, por exemplo. 
Para tentar explicitar essas suspeitas é que tomamos, como exemplo, enunciados em torno da Profilaxia Pré-exposição - PrEP, a partir das quais esse duplo analítico (capturas e resistências) pode ser vislumbrado. Assim, lançamos as perguntas a fim de pensar o problema nessa ambivalência analítica: a) como a viabilidade moral-econômica dos corpos e práticas sexuais LGBT, exercida na atualidade por meio de uma lógica fármaco-moralizante, se conecta com a governamentalidade biopolítica neoliberal e com a lógica de inclusão contemporâneos?; b) em que medida corpos e práticas buscam tensionar a própria lógica fármaco-moralizante, no momento em que fazem um uso estratégico de tais medidas de prevenção, constituindo, assim, outras moralidades?

\section{Governamentalidade biopolítica em Michel Foucault}

Os pais governam as crianças, a amante governa seu amante, o professor governa etc. Governamo-nos uns aos outros em uma conversação, através de toda uma série de táticas. Creio que esse campo de relações é muito importante e é isso que quis colocar como problema. Como isso se passa, por que instrumentos, e visto que, em um sentido, sou um historiador do pensamento e das ciências, de que efeitos são essas relações do poder na ordem do conhecimento? É esse o nosso problema. Michel Foucaultxiii

Ao tomar os sujeitos da diversidade sexual como sujeitos de direito, as políticas de tolerância e inclusão contemporâneas operam/operavam parodoxalmente em duas direções opostas, mas visceralmente complementares: a primeira direção é a de conceder determinados direitos civis, jurídicos, médicos a gays, lésbicas, bissexuais, travestis e transexuais, uma reivindicação da militância inegavelmente importante diante do processo histórico de violência e negação das garantias fundamentais da vida dessas pessoas; a segunda direção é, em uma espécie de "dou com uma mão e tiro com a outra", estabelecer em suas diretrizes formas bastante homogêneas e bem definidas de reconhecimento das identidades de gênero e sexuais. Essa segunda direção, parece-nos, acaba por cristalizar um determinado modelo identitário considerado correto, honrado, digno e merecedor de tais políticas, bem como por promover, em função dessa cristalização, formas de governamento dos sujeitos da diversidade sexual, cujo objetivo principal será não só o de conduzir sua conduta, mas também o de fazer com que eles mesmos conduzam suas vidas em direção à viabilização de seus corpos e práticas ao que Sierra (2013), chama de "uma moral sexual e de uma economia do corpo e das práticas".

Nesse sentido, os aportes foucaultianos sobre a noção de governamentalidade são fundamentais nesse processo de caracterização das formas de governamento dos sujeitos da diversidade sexual a que nos referimos. Ao possibilitar uma nova compreensão das relações de poder, a noção de governamentalidade irá sublinhar a questão do sujeito e suas formas de governamento ou, melhor dizendo, os diferentes modos pelos quais alguém se torna sujeito de ou assujeitado a, tanto em relação aos outros quanto a si mesmo. 


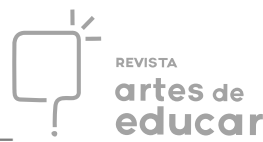

Desse modo, em função da ambiguidade que o termo governo implicava, ora podendo referir-se ao governo de um indivíduo sobre o outro (mais próximo do campo político) ora podendo referir-se ao governo de alguém sobre si mesmo (mais próximo do campo ético) foi preciso que Foucault criasse a expressão governamentalidade $^{x i v}$ (até então não presente em seu vocabulário) para caracterizar as novas formas administrativas de governamento da população, escapando de uma análise operada a partir de conceitos exclusivamente ligados à figura do Estado e suas instituições. Com isso, Foucault conseguiu mostrar "[...] a importância de deixar de lado a figura do poder do Estado onipotente e onipresente, capaz de controlar todos os recantos do social, em nome de técnicas difusas para governar os indivíduos em diferentes domínios.” (DUARTE, 2010, p.236), uma vez que “[...] nunca se governa um Estado, nunca se governa um território, nunca se governa uma estrutura política. Quem é governado são sempre pessoas, são homens, são indivíduos ou coletividades." (FOUCAULT, 2008b, p.164).

Embora Foucault já manifestasse interesse em relação à ideia de governo como arte de conduzir condutas, tanto no curso Os anormais como no curso Em defesa da sociedade, será mesmo em Segurança, território, população, curso de 1978, que essa ideia ganhará contornos mais definidos e uma análise mais específica de suas características. Nesse curso, Foucault desenvolve uma análise das formas de governo que vai do platonismo ao poder pastoral cristão, com o intuito de mostrar o que poderíamos chamar de uma história da governamentalidade que desembocará na constituição da razão de Estado. A noção de governamentalidade, portanto, tem a ver com a análise de Foucault sobre como se constituíram no âmbito do Estado moderno novos mecanismos de vigilância, controle e intervenção sobre a vida das populações, fruto de novas estratégias entre o Estado, a economia política e os dispositivos de seguridade. Para o autor, governamentalidade refere-se a um

[...] conjunto constituído pelas instituições, os procedimentos, análises e reflexões, os cálculos e as táticas que permitem exercer essa forma bem específica, embora muito complexa, de poder que tem por alvo principal a população, por principal forma de saber a economia política e por instrumento técnico essencial os dispositivos de segurança. Em segundo lugar, por "governamentalidade" entendo a tendência, a linha de força que, em todo o Ocidente, não parou de conduzir, e desde há muito, para a preeminência desse tipo de poder que podemos chamar de "governo" sobre todos os outros - soberania, disciplina - e que trouxe, por um lado, o desenvolvimento de toda uma série de aparelhos específicos de governo [e, por outro lado], o desenvolvimento de toda uma série de saberes. Enfim, por "governamentalidade", creio que se deveria entender o processo, ou antes, o resultado do processo pelo qual o Estado de justiça da Idade Média, que nos séculos XV e XVI se tornou o Estado administrativo, viu-se pouco a pouco "governamentalizado". (FOUCAULT, 2008b, p.143-144). 
Governamentalidade passa a figurar, portanto, no interior da obra foucaultiana, como uma grade de leitura por meio da qual é possível entender o poder em um aspecto mais amplo em relação a suas abordagens anteriores sobre, por exemplo, o poder soberano, o poder disciplinar, o biopoder, ou seja,

“[...] una 'grilla de inteligibilidad' de las relaciones de poder en su conjunto; no solo de aquellas que tiene que ver con la conducción de la conducta de otros en el hospital, en el taller, en la escuela, etc., sino también de aquellas que se refieren a la conducción de un Estado, de un 'cuerpo social'.” (CASTRO-GOMÉZ, 2010, p. 54).

Ao caracterizar o que chama de práticas de governamento, Foucault trabalhará em duas análises complementares sobre as relações de poder que, agora, no escopo de suas problematizações sobre governamentalidade, abarcarão não só uma analítica do poder diante da interrogação "[...] como, desde quando e por que se começou a perceber ou a imaginar que é a guerra que funciona sob e nas relações de poder?" (FOUCAULT, 2002, p. 54), mas também uma analítica do poder que acederá, em analogia com o poder pastoral cristão, a uma análise que preterirá a dimensão institucional do Estado em favor de uma ideia de governo mais ampla, que age tanto do ponto de vista molecular, como molar. Isso possibilitará, inclusive, uma reconfiguração da noção de biopolítica, “[...] tomando como como fio condutor a noção de governo, isto é, tipos de racionalidade que envolvem conjuntos de procedimentos, mecanismos, táticas, saberes, técnicas e instrumentos destinados a dirigir a conduta dos homens.” (GADELHA, 2009, p.120).

Em vista disso, a biopolítica, ao se inscrever na ordem das estratégias envolvidas para a efetivação das ações do biopoder ${ }^{\mathrm{xv}}$, articulará efeitos de governamento não só em relação a comportamentos individualizados, mas também em relação a práticas que visam a própria espécie em seus mais variados fenômenos populacionais.

\section{A profilaxia pré-exposição - PrEP, as formas de governamento biopolítico e a produção da viabilidade-moral-econômica dos sujeitos LGBT}

A Profilaxia Pré-exposição - PrEP, no contexto brasileiro, tem sido desenvolvida na forma de uma ampla pesquisa chamada PrEP Brasil, um estudo liderado pelo laboratório LapClin Aids, da Fundação Oswaldo Cruz - Fiocruz/RJ, cujo objetivo é administrar medicamentos antirretrovirais em pessoas soronegativas voluntárias a participar da pesquisa, como uma estratégia para reduzir o risco de infecção pelo HIV através de relações sexuais e, posteriormente, acompanhar os efeitos e resultados desse experimento. Dados disponíveis na seção "Informe-se", em seu portal na Internet, explicam que: 
A Profilaxia Pré-exposição (PrEP) ao vírus da imunodeficiência humana, o HIV, é uma estratégia de prevenção que envolve a utilização de um medicamento antirretroviral (ARV), por pessoas não infectadas, para reduzir o risco de aquisição do HIV através de relações sexuais. O medicamento ARV irá bloquear o ciclo da multiplicação desse vírus, impedindo a infecção do organismo.

Há duas formas principais de PrEP: a PrEP Oral em forma de comprimido e a PrEP Tópica em forma de gel. Os resultados iniciais dos ensaios clínicos de PrEP Oral indicam que essa estratégia de prevenção pode ser extremamente útil para a mudança de cenário necessária no combate a infecção pelo vírus HIV.

A PrEP Oral baseia-se no uso de medicamentos ARV para a prevenção da aquisição do HIV e sua eficácia parcial foi demonstrada entre homens que fazem sexo com homens (HSH) e heterossexuais. Intervenções de prevenção biomédica, como a PrEP, têm um grande potencial, especialmente se combinadas a testagem anti-HIV ampliada (mensal ou trimestral), diagnóstico e vinculação ao tratamento daqueles identificados como infectados pelo HIV.

[...]

A profilaxia pré-exposição ao HIV (PrEP), é uma estratégia de prevenção que envolve a utilização diária de um medicamento antirretroviral (ARV), por pessoas não infectadas, para reduzir o risco de aquisição do HIV através de relações sexuais. $\mathrm{O}$ estudo PrEP Brasil vai avaliar a aceitação, a viabilidade e a melhor forma de oferecer a PrEP à população brasileira como prevenção ao HIV.

Neste estudo serão incluídos 500 homens que fazem sexo com homens (HSH), travestis e mulheres transexuais com risco de adquirir a infecção pelo HIV.

Todos os participantes serão acompanhados por equipe especializada de médicos, enfermeiros e psicólogos durante todas as visitas do estudo.

Além do Truvada ${ }^{\circledR}$, que deverá ser usado diariamente, os participantes terão acesso a aconselhamento para gerenciamento do risco de adquirir a infecção pelo HIV, testes de HIV e de outras doenças sexualmente transmissíveis (DSTs). Exames laboratoriais também serão realizados para detectar eventuais efeitos colaterais. Adicionalmente testes que detectam material genético do HIV serão utilizados para identificar precocemente a infecção pelo HIV. Preservativos e lubrificantes serão sempre fornecidos e o uso deles fortemente incentivado. (Fonte: www.prepbrasil.com.br. Acesso em 17/04/2020).

Além disso, há em seu portal na Internet, toda a caracterização sobre o estudo, as ações desenvolvidas, cidades onde a pesquisa já conseguiu voluntários (Rio de Janeiro, São Paulo e Porto Alegre), os centros/hospitais participantes, bem como campanhas e vídeos que pretendem explicar o que é o estudo e seus objetivos.

Chama a atenção, contudo, quem são as pessoas elegíveis para o estudo, bem como os requisitos para poder participar da pesquisa, conforme consta em seu portal na Internet:

- Homens que fazem sexo com homens (HSH), travestis e mulheres transexuais;

- Ter idade igual ou superior a 18 anos;

- Não ser infectado por HIV-1;

- Ser disposto e capaz de fornecer consentimento livre e esclarecido* por escrito;

- Possuir qualquer uma das seguintes evidências de risco para aquisição de infecção pelo HIV-1: 
1. Ter praticado sexo anal sem preservativo com 2 ou mais homens ou mulheres transexuais nos últimos 12 meses; ou

2. Ter dois ou mais episódios de sexo anal com pelo menos um parceiro HIV+ nos últimos 12 meses; ou

3. Ter praticado sexo com um homem ou mulher transexual e possuir diagnóstico de qualquer uma das seguintes doenças sexualmente transmissíveis nos últimos 12 meses: sífilis, gonorreia retal ou infecção por clamídia no reto.

(Fonte: www.prepbrasil.com.br. Acesso em 17/04/2020).

Mesmo diante dessas informações disponibilizadas pelo próprio portal, o que por si só já daria uma pertinente discussão, o que nos interessa aqui não é fazer uma análise que pretenda problematizar a metodologia utilizada na/pela pesquisa $\operatorname{PrEP}$ Brasil, tampouco, tentar verificar a eficácia do tratamento como forma de prevenção ao vírus - até porque já há estudos (muitos deles disponibilizados no próprio site da pesquisa), que pretendem avaliar as potencialidades clínicas da iniciativa. Além disso, não é nosso objetivo, também, levantar uma problematização sobre o peso que a indústria farmacêutica tem em pesquisas dessa natureza e em que medida essa indústria financia e/ou colabora com essas pesquisas (o que seria um movimento de análise posterior, a ser realizado em outros estudos). Do mesmo modo, também não objetivamos entrar em uma discussão mais de ordem política, naquilo que se refere à dificuldade que, ainda hoje, pesquisas como essa têm, em função de preconceito e discriminação em relação a determinados grupos sociais, em se tornarem políticas públicas de Estado.

O que pretendemos, mais modestamente, é algo que, mesmo se relacionando com as questões acima, passa por um outro caminho. Queremos propor um ensaio (tanto naquilo que o termo carrega enquanto gênero de escrita, quanto naquilo que tem a ver com uma ideia ainda em construção), para pensar os efeitos biopolíticos de abordagens de prevenção como essas no contexto de nossa governamentalidade biopolítica neoliberal. Tais efeitos, ao nosso ver, relacionam-se com os processos de condução da conduta de subjetividades LGBT, que sinalizariam para um controle de seus corpos e práticas, por meio de uma lógica fármaco-moralizante.

Para tanto, focamos na análise especialmente em alguns depoimentos de voluntários anônimos ${ }^{\mathrm{xvi}}$ que o próprio portal PrEP Brasil disponibiliza, de forma pública, na Internet:

O que me motivou a participar como voluntário do estudo foi, obviamente, o meu envolvimento com o tema da AIDS. Além disto, pesaram o desejo de contribuir com o avanço da ciência e a erradicação do vírus HIV; a experiência enquanto usuário desta nova medicação e o pacote de atenção que a Fiocruz oferecia.

A PrEP melhorou muito a minha vida sexual e eliminou a preocupação e a ansiedade que eu tinha com o HIV. Eu nunca consegui me adaptar direito a usar camisinha e transo bastante sem camisinha, com vários parceiros. Antes de começar a PrEP eu sentia culpa e medo depois de cada transa sem camisinha. Cada exame de HIV era um suplício. Já cheguei a ficar no telefone com um amigo 
enquanto aguardava o resultado de um teste para eu poder desabafar e chorar se desse positivo. Outro medo que eu tinha era passar HIV para alguém. Essa ideia me assustava ainda mais do que descobrir que eu tinha HIV. Hoje não me preocupo mais com HIV. Os exames de HIV são só mais uma rotina, sem suspense e sem medo. Eu já sei que o resultado vai ser sempre negativo. Outro efeito da PrEP é que me sinto mais à vontade para me relacionar com homens soropositivos. Hoje não faz diferença se meus parceiros sexuais são positivos ou negativos, pois sei que estou sempre protegido, aconteça o que acontecer. Sei que eu vou continuar negativo. Para mim, a PrEP significou liberdade, tranquilidade e paz. É uma maneira de me manter saudável e de manter meus parceiros saudáveis. Estou conseguindo tomar o Truvada todo dia e não tive nenhum efeito colateral. Sou extremamente grato pela PrEP e quero que ela faça parte da minha vida enquanto for necessário. O PrEP Brasil dura só um ano, mas quando acabar pretendo procurar um médico e importar o remédio. Não quero parar de tomar nem por um dia. Não quero voltar para aquela rotina de ansiedade $e$ medo.

Sou da geração 90. Sempre ouço que porque não vimos as mortes dos anos 80 provocadas pela AIDS, não usamos camisinha - daí os altos níveis de incidência de HIV em jovens. Eu nunca achei que eu deveria ter nostalgia de um tempo que não vivi. Eu não quero relembrar a dor dos meus pares, das milhares de mortes que aconteceram no passado. Eu quero que ninguém precise usar a nostalgia para se safar da falta de compreensão da Epidemia no presente. Ela é temporal. Eu também não quero me prevenir do HIV pelo medo. Pelo contrário, quero que ele desapareça do nosso sexo, do nosso desejo e das nossas fantasias. A verdade é que o PrEP me permite fazer o que desejo sem a mesquinha nostalgia da dor, do medo e da morte.

Alteração de rotina diária, apenas na disciplina de tomar todos os dias no mesmo horário, o que até agora (há 1 mês) não foi problema pois nunca perdi uma dose e nem atrasei nunca. Agora sexualmente falando, sou obrigado a dizer e sem falso moralismo, que me senti mais confiante e com menos medo de me relacionar sexualmente. No restante, nada demais, efeitos colaterais até agora ZERO.

(Fonte: www.prepbrasil.com.br. Acesso em 17/04/2020, grifos nossos).

Os depoimentos acima, demonstram que a relação de medo que a Aids historicamente estabeleceu não desapareceu com tempo, especialmente entre aquelas pessoas que viveram sua juventude nos anos 1980 e 1990, época em que a doença era tida como uma sentença de morte. Não é à toa que termos como "medo" e "culpa" apareçam nos depoimentos.

Tais expressões, que durante muito tempo traduziram as vidas de pessoas LGBT em sua relação com a Aids, até hoje, de alguma forma, ecoam quando o assunto é o vírus, suas formas de contágio, prevenção e tratamento. Para uma geração que viu pessoas definhando publicamente em função da doença, como na histórica capa de Cazuza, na revista Veja, esses sentimentos ainda persistem fortemente. "Medo" porque a doença sempre foi enunciada como algo implacável, seja do ponto de vista físico-clínico, mesmo com os recentes tratamentos que possibilitam uma vida soropositiva saudável; seja do ponto de vista dos 
julgamentos morais a que uma pessoa soropositiva está submetida, apesar das diversas campanhas de conscientização em torno da doença. E “culpa” especialmente pela pressão de alguns setores conservadores e religiosos, tanto pelo fato de contaminar-se, quanto de contaminar outras pessoas, que pode vir a gerar, inclusive, depressão, como vemos nos depoimentos dos voluntários.

Medo e culpa se convertem, assim, em sentimentos que, discursivamente, levam os sujeitos LGBT a perceberem-se (e a serem percebidos), mesmo depois dos anos críticos e de grande estigmatização nas décadas de 1980 e 1990, não só como desviantes das normas de gênero e sexuais, mas também como sujeitos que colocariam em risco sua vida e das demais pessoas, em função de como sentem e vivem seus corpos e seus prazeres. É como se a própria noção de existência de cada pessoa fosse responsável em articular, a partir de determinados atributos essencializadores, as tecnologias de controle.

Nesse sentido, uma das formas pelas quais se exerce o controle do Estado sobre a população (as famílias) [mas poderíamos nesse caso dizer também a população LGBT] inclui a delimitação de características e atributos a serem inscritos nos corpos de mulheres e homens por premissas que se articulam com a noção de existência de uma suposta essência - em geral caracterizada como biológica e/ou psicológica na área da saúde - masculina ou feminina. Sentimentos e comportamentos sociais representados por alguns grupos como verdadeiros e válidos podem se tornar imperativos em políticas e propostas de educação e(m) saúde direcionadas para o conjunto da população ou para outros grupos que fazem parte dela. (KLEIN; MEYER; BORGES, 2013, p. 909)

Desse modo, corpos que não se submetam ao tratamento, ou práticas sexuais ditas inseguras que podem gerar risco de contaminação, se tornariam inviáveis socialmente, seja do ponto de vista econômico (um corpo "doente" gera despesas ao Estado), seja do ponto de vista moral (práticas sexuais dissidentes geram risco à saúde dos outros e de si mesmo).

Em função disso, os sujeitos LGBT são interpelados a se ajustarem a dois princípios: a) a uma certa moral $^{x v i i}$, que prescreve quais corpos, quais práticas e quais prazeres sexuais são corretos, honrados, saudáveis, seguros e aceitáveis, tanto diante das recomendações dos movimentos sociais, das políticas públicas de Estado ou de Pesquisas como o PrEP Brasil; e b) a uma certa ecomomia, que institui quais corpos, quais práticas e quais prazeres atendem ao projeto de utilidade-rentabilidade que a ordem do consumo e do trabalho neoliberais apregoam como necessárias ao projeto de consolidação do sujeito de direito e de sua viabilidade-moral-econômica.

A caracterização que Foucault faz acerca da ideia de moral ligada a determinadas formas de comportamento pode nos ajudar a ampliar a discussão sobre a viabilidade moral dos sujeitos LGBT. Se para Foucault, por um lado, o termo "moral" pode referir-se a um código de prescrições de valores e regras coesas de ação que são transmitidos aos indivíduos por instituições sociais, as quais permitem negociações e compromissos, por outro lado, também pode significar “[...] o comportamento real dos indivíduos em 
relação às regras e valores que lhes são propostos: designa-se, assim, a maneira pela qual eles se submetem mais ou menos completamente a um princípio de conduta." (FOUCAULT, 2001b, p. 26).

De alguma forma, essa noção tem a ver com primeira pergunta desse artigo, e que aparece refletida nos depoimentos dos voluntários acima: "O que me motivou a participar como voluntário do estudo foi, obviamente, o meu envolvimento com o tema da AIDS"; "Antes de começar a PrEP eu sentia culpa e medo depois de cada transa sem camisinha", "Outro medo que eu tinha era passar HIV para alguém", "Estou conseguindo tomar o Truvada todo dia e não tive nenhum efeito colateral", "A verdade é que o PrEP me permite fazer o que desejo sem a mesquinha nostalgia da dor, do medo e da morte."

Ao recorrermos a esses depoimentos, quando falamos de uma certa moral que liga os sujeitos LGBT aos processos de governamento biopolítico que os tornam viáveis na lógica heteronormativa e no contexto neoliberal, nos referimos a um tipo de moral que se associa à prescrição de um determinado código de condutas que é seguido como lei por um conjunto de pessoas. É aquilo que Foucault (2001b) chama de "moralidade dos comportamentos". Nesse sentido, cabe ressaltar que para o projeto heteronormativo de constituição do corpo viável e das práticas saudáveis e seguras, haverá sempre alguns corpos que serão considerados inviáveis e algumas práticas que serão consideradas inseguras, em função de sua impossibilidade de classificação, ordenação e normalização.

Tais corpos e práticas inviáveis são considerados inúteis (portanto descartáveis) à dinâmica que governa vidas e condutas. Só é possível governar aquilo que, de certa forma, se converte em algo reconhecível e inteligível. Por isso, inclusive, os reclames de diversidade sexual e de gênero apelam para as formas identificáveis de vida - justamente aquelas que, por reconhecimento identitário, poderão fazer parte de programas de promoção da saúde e promoção da cidadania (como o PrEP Brasil) - e estabelecem quais são e quais não são as formas de desejo consideradas legítimas e cabíveis. Cabe lembrar que, no contexto neoliberal, o desejo passa a ser um elemento fundamentalmente governável e esse governo é importante para a implementação dos dispositivos de seguridade, conforme diz Castro-Goméz (2010, p.82): “Hay que 'dejar pasar' el deseo, pero dentro de ciertos limites, pues esto redundará en benefício de los objetivos gubernamentales del Estado."

Essa regulamentação do desejo opera, assim, no sentido não só de controlar o sexo e a sexualidade no que se refere à prevenção de doenças e a controles epidemiológicos, como também de prescrever quais comportamentos são aceitáveis e "morais" e quais comportamentos serão considerados perigosos, “imorais". Perigosos não só porque podem ser alvo fácil para o contágio por algum tipo de doença (o que oneraria o Estado), mas também porque poderiam impedir a consolidação de um projeto no qual não cabe nenhum corpo e nenhuma prática sexual que não esteja já prevista, descrita e limitada a partir da moral heterossexual (que dita quais seriam os bons comportamentos), bem como não se inscreva nas tecnologias 
de gênero/sexuais que passam a operar, no contexto da governamentalidade neoliberal, como agentes biopolíticos de controle do sexo, do corpo e das práticas sexuais.

No que se refere à viabilidade econômica dos sujeitos LGBT, cabe dizer, ainda, que essa ideia está conectada ao conceito de "capital humano" (FOUCAULT, 2008a) que, em certa medida, coloca-se também como responsável pela produção de identidades normatizadas que atenderão não apenas aos desígnios morais heteronormativos, mas também aos aparatos do mercado (no caso da Profilaxia Pré-exposição $\operatorname{PrEP}$, a indústria farmacêutica), que regulam a produção desse sujeito como ativamente econômico e viável. Para Gadelha Costa (2009), quando falamos em uma economia política, estamos nos referindo ao “[...] trabalho exercido pelos indivíduos como uma conduta econômica, e de tentar entender como essa conduta é praticada, racionalizada e calculada por aquele que a exerce.” (p. 176).

Esse argumento sinaliza para como tem acontecido o processo de inclusão dos sujeitos da diversidade sexual na lógica da relação custo/benefício que articula um tipo de governamentalidade que, agora, no contexto neoliberal, vem sendo o de programar estrategicamente todo tipo de comportamento dos indivíduos (especialmente o de prevenção e práticas sexuais seguras), agindo diretamente na forma desses indivíduos sentirem, pensarem, viverem seus corpos, suas práticas sexuais e seus prazeres. Um tipo de governamentalidade que promoverá formas de subjetivação que se inscreverão no modus operandi da administração, das dinâmicas de grupo psicológicas, dos livros de autoajuda, da publicidade e dos princípios de mercado como o lugar privilegiado a reger e a conduzir não só a sociedade como um todo, mas também cada indivíduo em particular. "E é esse lugar mesmo, e não a teoria econômica, que, a partir do século XVIII, vai se tornar um lugar e um mecanismo de formação de verdade. [...] Esse lugar de verdade não é, evidentemente, a cabeça dos economistas, mas o mercado.” (FOUCAULT, 2008a, p.42).

\section{A profilaxia pré-exposição - PrEP, outros usos dos corpos, outras práticas sexuais e as estratégias de resistência}

Diante das formas de governamento biopolítico é que se justifica um ensaio de novas formulações voltadas para o questionamento do modelo identitário. Não só fazer uma problematização e mostrar os limites do sujeito universal do feminismo (como fizeram as feministas nos anos 1970) nem, tampouco, somente indicar os problemas que a noção de um sujeito "homossexual verdadeiro" trouxe para os Estudos Gays e Lésbicos nas décadas anteriores. As novas formulações que pretendem questionar a lógica identitária e seus afluentes (a produção de corpos e práticas viáveis, a noção de um sujeito de direito e a inclusão do sujeito da diversidade sexual na esfera social) talvez pudessem, agora, inscreverem-se em outros modos de operação, privilegiando formas de resistência que oferecessem outros questionamentos diante dos processos de normalização, bem como das formas que historicamente têm promovido a captura 
das sexualidades dissidentes pelas tecnologias normalizadoras, nas quais a lógica fármaco-moralizante está inserida.

Por considerarmos, como nos diz Foucault, que do interior mesmo das relações de poder é que surgem as práticas de resistência, queremos aventar que, em alguma medida, mesmo que inserida nesse lugar do governamento biopolítico, a Profilaxia Pré-exposição - PrEP pode, também, da forma como temos interpretado, estar funcionando como possibilidade para que determinados corpos criem outras relações entre si.

Essas novas relações, da maneira como percebemos, não estão ligadas às definições de moral já explicitadas anteriormente; ao contrário, elas têm a ver com uma outra definição feita por Foucault a respeito dessa ideia: aquela por meio da qual cada um se constitui como sujeito moral na medida em que age tendo como referência os elementos prescritivos. Assim, moral se refere tanto a um código, quanto ao agente, ao modo como os indivíduos se relacionam com tal código e o põe em prática, o que, por sua vez, abre ainda uma outra via de consideração do significado de moral: a discussão da constituição de si como indivíduo moral, o modo como o indivíduo conduz a si mesmo em face ao código, pois há várias formas possíveis de estar em concordância com determinado código de prescrições.

Neste caso, o significado de moral nos permite pensar o "[...] modo de sujeição, isto é, a maneira pela qual o indivíduo estabelece sua relação com essa regra e se reconhece como ligado à obrigação de pôla em prática" (FOUCAULT, 2001b, p. 26). Ao analisar o modo de sujeição do indivíduo ao código, Foucault abre espaço para considerar a atividade autônoma do sujeito que se assujeita ao código e, assim, se distingue dos demais, reconhecendo-se como sujeito moral. Ele não obedece simplesmente à regra: o faz de determinado modo e por determinados motivos, motivos e modos determinados por ele mesmo, de onde vem a ideia de autonomia.

Aqui, talvez, abra uma possibilidade para problematizarmos - mesmo que de forma a lançar o argumento para futuros trabalhos - se a Profilaxia Pré-exposição - PrEP também não se configura como uma estratégia a partir da qual as pessoas podem criar outras formas de se relacionar, tanto com os outros, quanto consigo mesmo. Uma espécie de trincamento, rachadura no interior da própria lógica fármacomoralizante, em que a busca pela autonomia do corpo, das práticas e dos prazeres seja o objetivo ao aderir ao tratamento.

Se, ao menos em tese, a profilaxia pode evitar o contágio da doença em relações sexuais, esta forma de prevenção pode possibilitar aos sujeitos outras experimentações dos corpos e dos prazeres, inclusive entre casais monogâmicos sorodiscordantes, por exemplo. Nos parece que os depoimentos dos voluntários, em alguma medida, também sinalizam isso: "Outro efeito da PrEP é que me sinto mais à vontade para me relacionar com homens soropositivos. Hoje não faz diferença se meus parceiros sexuais são positivos ou negativos, pois sei que estou sempre protegido, aconteça o que acontecer", "Para mim, a PrEP significou 
liberdade, tranquilidade e paz. É uma maneira de me manter saudável e de manter meus parceiros saudáveis" "A verdade é que o PrEP me permite fazer o que desejo sem a mesquinha nostalgia da dor, do medo e da morte". "Agora sexualmente falando, sou obrigado a dizer e sem falso moralismo, que me senti mais confiante e com menos medo de me relacionar sexualmente".

Se em toda moral encontram-se os aspectos da codificação e dos modos de sujeição ao código, é preciso marcar o aspecto sobre o qual recai a diferenciação entre sistemas morais distintos entre si. Há morais nas quais a importância recai sobre a codificação, ressaltando-se sua sistematização e ordenação, isto é, a “[...] subjetivação se efetua, no essencial, de uma forma quase jurídica, em que o sujeito moral se refere a uma lei ou a um conjunto de leis às quais ele deve se submeter sob pena de incorrer em faltas que o expõem a um castigo." (FOUCAULT, 2001b, p. 29). Em contrapartida, também há morais nas quais a tônica não se encontra no quadro das prescrições, mas sim no modo como cada indivíduo se submete aos códigos, ressaltando-se o processo auto-criador e autônomo da vida.

Em suma, para ser dita "moral" uma ação não deve se reduzir a um ato ou a uma série de atos conformes a uma regra, lei ou valor. É verdade que toda ação moral comporta uma relação ao real em que se efetua, e uma relação ao código a que se refere; mas ela implica também uma certa relação a si; essa relação não é simplesmente "consciência de si", mas constituição de si enquanto "sujeito moral", na qual o indivíduo circunscreve a parte dele mesmo que constitui o objeto dessa prática moral, define sua posição em relação ao preceito que respeita, estabelece para si um certo modo de ser que valerá como realização moral dele mesmo; e, para tal, age sobre si mesmo, procura conhecer-se, controlar-se, põe-se à prova, aperfeiçoa-se, transforma. (FOUCAULT, 2001b, p. 26).

Os trechos de depoimentos acima parecem indicar esse segundo caso, ou seja, morais que se voltam à ética e remetem-se "[...] às formas das relações consigo, aos procedimentos e às técnicas pelas quais são elaboradas, aos exercícios pelos quais o próprio sujeito se dá como objeto a conhecer, e às práticas que permitam transformar seu próprio modo de ser." (FOUCAULT, 2001b, p. 30).

Eis aqui, portanto, um ponto fundamental: mesmo diante de práticas de governo biopolítico dos outros e de si mesmo, é possível arriscar pensar outras formas de lutar e resistir, gerando tensão no modelo de inclusão que sustenta a noção de diversidade sexual e de gênero atual, em favor de um outro pensamento que nos lance à busca por outros modos de vida. Uma busca capaz de esgarçar os mecanismos de governamento que promovem a viabilidade-moral-econômica dos sujeitos LGBT e que ajusta - ao mesmo tempo que normaliza - seus corpos, suas práticas sexuais e seus prazeres às biopolíticas neoliberais contemporâneas. Tal busca, quem sabe, possa recolocar o exercício da resistência no interior mesmo das relações de poder, ressignificando nossas ações, seja no campo da educação, seja no campo da saúde, dois lugares indiscutivelmente tão atrelados ao processo de subjetivação dos corpos. Essas ações talvez consigam curto-circuitar o essencialismo subjetivo tão presente hoje em dia e que corrobora para marcar 


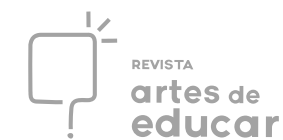

uma ideia de democracia, cidadania e de direito à educação e à saúde que pactua, mesmo com as conquistas já obtidas, com as formas de governamento e captura do outro. Uma busca, enfim, capaz de instabilizar as configurações biopolíticas contemporâneas para mirar a possibilidade de criar outras experimentações, outros corpos, outras práticas, outros prazeres.

\section{Referências}

CASTRO-GOMÉZ, Santiago. Historia de la gubernamentalidad. Razón de Estado, liberalismo y neoliberalismo en Michel Foucault. Bogotá: Siglo del Hombre Editores; Pontificia Universidad JaverianaInstituto Pensar; Universidad Santo Tomáz de Aquino, 2010.

CÉSAR, Maria Rita de Assis. (Des)governos... biopolítica, governamentalidade e educação contemporânea. In: ETD. Educação Temática Digital. V. 12, 2010; p. 224-241.

DUARTE, André. Vidas em Risco. Crítica do presente em Heidegger, Arendt e Foucault. Rio de Janeiro: Forense Universitária, 2010.

FACHINNI, Regina. Sopa de Letrinhas: movimento homossexual e produção de identidades coletivas nos anos 90. Rio de Janeiro. Garamond, 2005.

FOUCAULT, Michel. O intelectual e os poderes. In: . Ditos \& Escritos. Vol. VI. Repensar a Política. Rio de Janeiro: Forense Universitária, 2010.

FOUCAULT, Michel. Nascimento da biopolítica. São Paulo: Martins Fontes, 2008a.

FOUCAULT, Michel. Segurança, território, população. São Paulo: Martins Fontes, 2008b.

FOUCAULT, Michel. Em defesa da sociedade. São Paulo: Martins Fontes, 2002.

FOUCAULT, Michel. História da Sexualidade: a vontade de saber. V. 1. 14 ed. Rio de Janeiro: Graal, $2001 \mathrm{a}$.

FOUCAULT, Michel. História da Sexualidade: o uso dos prazeres. V. 2. 9 ed. Rio de Janeiro: Graal, $2001 \mathrm{~b}$. FOUCAULT, Michel. Herculine Barbin: o diário de um hermafrodita. Rio de Janeiro: Francisco Alves, 1982.

GADELHA, Sylvio. Biopolítica, governamentalidade e educação: introdução e conexões, a partir de Michel Foucault. Belo Horizonte: Autêntica, 2009.

KLEIN, Carin; MEYER, Dagmar Estermann; BORGES, Zulmira Newlands. Políticas de inclusão social no Brasil contemporâneo e educação da maternidade. In: Cadernos de Pesquisa. v. 43. n. 150, 2013, p. $906-$ 923.

MEYER, Dagmar Estermann; DAL'IGNA, Maria Cláudia; KLEIN, Carin; SILVEIRA, Catharina da Cunha. Políticas públicas: imperativos e promessas de inclusão social. In: Ensaio: Avaliação e Políticas Públicas em Educação. vol.22, n.85, 2014. p.1001-1026.

MISKOLCI, Richard. Pânicos morais e controle social - reflexões sobre o casamento gay. In: Cadernos Pagu (28), janeiro-junho de 2007. p. 101-128.

PELÚCIO, Larissa. Abjeção de Desejo: Uma etnografia travesti sobre o modelo preventivo de aids. São Paulo: Anablume-FAPESP, 2009. 
SANTOS, Luís Henrique Sacchi. Biopolíticas de HIV/AIDS no Brasil: uma análise dos anúncios televisivos das campanhas oficiais de prevenção: 1986-2000. Tese de doutorado. Universidade Federal do Rio Grande do Sul. Doutorado em Educação. 2002.

SIERRA, Jamil Cabral. Identidade e diversidade no contexto brasileiro: uma análise da parceria entre Estado e movimentos sociais LGBT de 2002 a 2015. In: Revista Anos 90. v. 26 - e2019302. Porto Alegre, 2019. p.1-14

SIERRA, Jamil Cabral. Marcos da vida viável, marcas da vida vivível: O governamento da diversidade sexual e o desafio de uma ética/estética pós- identitária para a teorização político-educacional LGBT. Tese (Doutorado em Educação) - Universidade Federal do Paraná. Curitiba, 2013b.

SIERRA, Jamil Cabral. Corpo, sexualidade e poder: a homossexualidade na mídia e as biopolíticas de prevenção contra a Aids. In: Textura. n.28, maio/ago 2013a. p.111 a 128.

SIERRA, Jamil Cabral. Campanhas de prevenção contra HIV/Aids entre homossexuais e a governamentalidade dos corpos e das práticas sexuais no discurso midiático. In: FERREIRA, Aparecida de Jesus. (Org.). Relações étnico-raciais, de gênero e sexualidade: perspectivas contemporâneas. Ponta Grossa: Editora UEPG, 2014. p.137-152

SPARGO, Tamsim. Foucault e a Teoria Queer. Rio de Janeiro: Pazulin; Juiz de Fora: Ed. UFJF, 2006.

VEIGA-NETO, Alfredo. Coisas de governo... In: RAGO, Margareth. ORLANDI, Luiz B. Lacerda; VEIGA-NETO, Alfredo. (Orgs.). Imagens de Foucault e Deleuze. Ressonâncias nietzschianas. Rio de Janeiro. DP\&A, 2002. p. 13-34.

TREVISAN, João Silvério. Devassos no Paraíso. A homossexualidade no Brasil, da colônia à atualidade. 5 ed. revista e ampliada. São Paulo: Record, 2002.

Recebido em: 22/04/2020.

Aceito em: 03/08/2020.

Notas

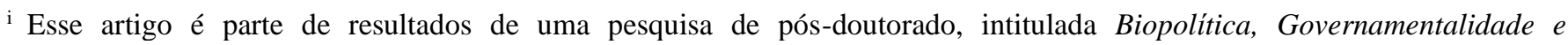
Medicalização das Sexualidades LGBT na interface Educação e Saúde: uma análise do Profilaxia Pré-exposição - PrEP Brasil, realizada no Programa de Pós-graduação em Educação, da UFRGS, entre 2016 e 2017, com financiamento do CNPq.

ii Doutor em Educação pela Universidade Federal do Paraná - UFPR e Professor Adjunto no Departamento de Planejamento e Administração Escolar - DEPLAE e no Programa de Pós-graduação em Educação - PPGE, do Setor de Educação da UFPR. Coordenador e pesquisador do GILDA - Grupo Interdisciplinar em Linguagem, Diferença e Subjetivação (UFPR/CNPq). Email: jamilcasi@gmail.com. ORCID: https://orcid.org/0000-0002-2137-7996

iii Doutora em Educação pela Universidade Federal do Rio Grande do Sul - UFRGS e Professora Aposentada do Programa de Pós-graduação em Educação - PPGEdu e da Faculdade de Educação da UFRGS. Foi integrante-fundadora do Grupo de Estudos de Educação e Relações de Gênero (GEERGE, de 1990 a 2019) e bolsista de Produtividade em Pesquisa do CNPq (2001 a 2018, nível 2 a 1B). E-mail: dagmaremeyer@gmail.com. ORCID: https://orcid.org/0000-0003-4182-3938

iv O termo "governamento" é usado aqui conforme Veiga-Neto (2002), para marcar a distinção que Foucault faz entre o que são instâncias administrativas de governo e ações de governar. 


\begin{abstract}
"Vejam, por exemplo, a polêmica que tomou conta do Brasil acerca da propalada "Ideologia de Gênero", que mobilizou tanto os movimentos sociais, quanto os setores mais conservadores do país sobre o debate em torno da discussão de gênero e sexualidade na escola. Sem querer entrar no mérito da questão, trago esse exemplo apenas para aludir a como tem se discutido a relação entre homossexualidade e educação e de como isso tem se feito pauta nos movimentos sociais contemporâneos.

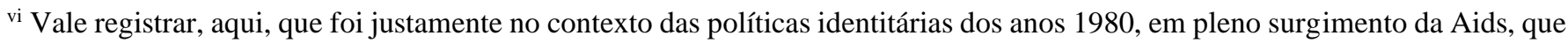
começamos a ter, de forma mais insistente e consistente (tanto política como teoricamente), um empreendimento de questionamento e revisão das políticas identitárias e das retóricas de inclusão da população LGBT, especialmente no campo da educação e da saúde.
\end{abstract}

vii Sobre a noção de pânico moral, especialmente ligada ao contexto LGBT, ver Miskolci (2007).

viii Publicada pela Organização Mundial de Saúde (OMS), a Classificação Estatística Internacional de Doenças e Problemas Relacionados com a Saúde, conhecida pela sigla CID é um documento que estabelece códigos relativos à classificação de doenças, seus sinais, sintomas.

ix No Brasil, especialmente a partir dos anos 2000, foram promovidas muitas campanhas de prevenção contra HIV/Aids, em especial aquelas direcionadas especificamente ao público LGBT: "Campanha Travestis", de 2002; "Campanha Homens que fazem sexo com homens", de 2002; "Plano Nacional de Enfrentamento da Epidemia de Aids e das DST entre Gays, HSH e Travestis", de 2008 que promoveu diversas campanhas naquele ano; "Campanha Sou Travesti. Tenho direito de ser quem sou", de 2010 e 2012; "Campanha do dia da visibilidade Trans", de 2013.

x Para mais sobre esse processo de constituição, ver Sierra (2019).

${ }^{x i}$ Sobre o impacto que a epidemia da Aids teve no contexto Brasileiro, ver também Santos (2002).

xii "Truvada® é um medicamento antirretroviral aprovado pelo Food and Drugs Administration (FDA), órgão semelhante à Agência Nacional de Vigilância Sanitária (ANVISA), para tratamento de HIV/Aids que combina dois medicamentos em um comprimido: o fumarato de tenofovir desoproxila (TDF, 300 mg) e a emtricitabina (FTC, $200 \mathrm{mg}$ )" Fonte: http://prepbrasil.com.br/o-truvada-um-comprimido-por-dia/ Acesso em $17 / 04 / 2020$.

xiii Foucault (2010, p.375).

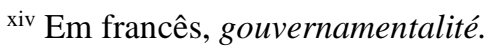

xv Apesar de haver autores que não fazem distinção entre os termos "biopolítica" e "biopoder", tendemos a marcar, em termos de operação conceitual, uma distinção: enquanto esse é da ordem das ações sobre a vida das populações, aquele é da ordem das estratégias envolvidas com a condução e a efetivação de tais ações.

xvi Mesmo que no site da pesquisa haja, em alguns casos, o nome publicado da pessoa que deu o depoimento, resolvemos, aqui, suprimi-los, já que o que nos interessa não é o sujeito empírico que enuncia, mas os sentidos que podem ser depreendidos de tais enunciados.

xvii Importante dizer, ainda, que essa moral muda um pouco em cada uma das estratégias e políticas de prevenção (camisinha ou PrEP). Não se pode perder de vista, desse modo, que a PrEP abre, ou reabre de algum modo, possibilidades de viver desejos e prazeres antes negados nos discursos de prevenção anteriores, como o da camisinha, por exemplo. 